Review

\title{
Origin, Impact and Control of Lignocellulosic Inhibitors in Bioethanol Production-A Review
}

\author{
Nikki Sjulander* and Timo Kikas(i) \\ Institute of Technology, Estonian University of Life Sciences, Kreutzwaldi 56/1, EE51006 Tartu, Estonia; \\ Timo.Kikas@emu.ee \\ * Correspondence: nikki.sjulander@emu.ee
}

Received: 11 August 2020; Accepted: 8 September 2020; Published: 11 September 2020

\begin{abstract}
Bioethanol production from lignocellulosic biomass is still struggling with many obstacles. One of them is lignocellulosic inhibitors. The aim of this review is to discuss the most known inhibitors. Additionally, the review addresses different detoxification methods to degrade or to remove inhibitors from lignocellulosic hydrolysates. Inhibitors are formed during the pretreatment of biomass. They derive from the structural polymers-cellulose, hemicellulose and lignin. The formation of inhibitors depends on the pretreatment conditions. Inhibitors can have a negative influence on both the enzymatic hydrolysis and fermentation of lignocellulosic hydrolysates. The inhibition mechanisms can be, for example, deactivation of enzymes or impairment of vital cell structures. The toxicity of each inhibitor depends on its chemical and physical properties. To decrease the negative effects of inhibitors, different detoxification methods have been researched. Those methods focus on the chemical modification of inhibitors into less toxic forms or on the separation of inhibitors from lignocellulosic hydrolysates. Each detoxification method has its limitations on the removal of certain inhibitors. To choose a suitable detoxification method, a deep molecular understanding of the inhibition mechanism and the inhibitor formation is necessary.
\end{abstract}

Keywords: bioethanol; detoxification; hydrolysates; lignocellulosic inhibitors; pretreatment; saccharomyces cerevisiae; yeast

\section{Introduction}

The 2nd generation bioethanol is produced from lignocellulosic biomass, like straw or wood. This kind of biomass does not compete with the food or feed industry and consequently mitigates the fuel-vs.-food debate, which is often discussed in case of the 1st generation bioethanol production from edible crops [1]. Although the usage of lignocellulosic biomass is eliminating this ethical food conflict, it is more complicated to utilize lignocellulosic biomass to produce bioethanol than agricultural crops. Especially, the dense and complex structure of lignocellulosic biomass hampers the production of bioethanol. To enable a proper utilization of lignocellulosic biomass, pretreatment is necessary. With the help of pretreatment, it is possible to break open the lignocellulosic structure and to increase the surface area of the biomass. More specifically, pretreatment loosens the tight matrix of the structural polymers in the lignocellulosic biomass and the increased surface area enables a better enzymatic hydrolysis of the polysaccharides. The sugars from those two polymers can then be used for producing bioethanol $[2,3]$.

Several different pretreatment methods have been developed, which use physical, chemical and biological techniques. During pretreatment, many different inhibitors can be formed, which can significantly decrease the efficiency of the subsequent production processes of bioethanol. Inhibitors mainly occur when the pretreatment method uses high temperatures, reactive chemicals and/or long pretreatment times. Additionally, the amount and the type of inhibitor depends on the used biomass [4]. 
Inhibitors can be roughly categorized into three main groups: short-chain organic acids and aldehydes, sugar-derived aldehydes, and aromatic compounds. The organic acids can originate from all main parts of the lignocellulosic biomass, for example, acetic acid from the acetyl-groups of hemicellulose [5]. The sugar-derived aldehydes-glycolaldehyde, furfural, and hydroxymethylfurfural (HMF) are formed, when pentose and hexose sugars degrade. The aromatic compounds mainly occur when lignin degrades. The toxicity of each inhibitor depends on its concentration, chemical polarity, and reactivity. Additionally, it has been reported that the presence of many different inhibitors in lignocellulosic hydrolysates has a much more pronounced inhibitory effect on microorganisms and enzymes than just one inhibitor alone [6-8].

In the last 20 years, many detoxification methods with different approaches have been researched. Some methods concentrate on the removal of inhibitors from hydrolysate broths. In this case, already well-known technical applications, like solid-phase adsorption, liquid-liquid extraction, and nanofiltration, are used [9-11]. Other methods focus on the chemical conversion of inhibitors into their less toxic forms, e.g., furfural to furfuryl alcohol [12]. The inhibitor conversion is accomplished with enzymes, chemicals, and genetically modified microorganisms $[13,14]$. The third approach is to optimize the whole hydrolysis and fermentation process to decrease the toxic effect of inhibitors. Additionally, the fermenting microorganism can be genetically engineered to more inhibitor resistant [15]. No single detoxification method is capable of removing every inhibitor from the hydrolysate broth completely. The removal efficiency of every method depends on the properties of the inhibitor, such as size, polarity, chemical reactivity, and concentration $[13,16]$. Besides that, the detoxification step is often accompanied by sugar losses, which reduces the overall efficiency of the bioethanol production [17].

Inhibitors should not be just considered as obstacles for fermentation and hydrolysis but could also be viewed as valuable chemicals for other industries [18]. Therefore, it might be important to prioritize extraction methods over decomposing methods. Overall, the inhibitor extraction would increase the cost effectiveness of bioethanol production from lignocellulosic biomass. In a lower concentration, some inhibitors might even enable a more efficient fermentation process with higher bioethanol yields. Hence, it should be considered whether it is necessary to remove all inhibitors [19].

The aim of this review is to list, analyze and discuss most of the known lignocellulosic-derived inhibitors. Additionally, the negative impacts and origins of the inhibitors will be described. The paper will also focus on the different methods developed for extracting or degrading inhibitors.

\section{Materials and Methods}

The used literature in this review paper was gathered by applying the PICO search strategy. After framing the PICO questions following search string with Boolean Operators was defined: inhibitor OR lignocellulosic biomass OR yeast OR saccharomyces cerevisiae OR bioethanol OR enzyme AND toxicity OR inhibition AND pretreatment OR hydrolysis OR fermentation AND reduction OR decontamination OR detoxification. The digital databases Web of Science, Scopus, CAB Direct, IEEE Xplore Digital Library, JSTOR, ScienceDirect, Taylor\&Francis e-journals, Wiley Online Library were searched. The obtained search results were sorted by relevance on the web pages. Depending on the number of search results on every web page, 63 to 500 of the first citations were downloaded into the bibliographic database software Zotero version 5.0.89 (George Mason University, Fairfax, VA, USA). The unimportant citations, which were not relevant to the discussed subject, were excluded by reading the title of the paper. Afterwards, the papers were filtered once more by reading their abstracts. Finally, the remaining papers were read and information summarized in this review paper.

\section{Inhibitors}

\subsection{Classification of Inhibitors}

The knowledge about lignocellulosic-derived inhibitors has increased in the last decades. Since then, the classification of inhibitors was extended and changed, because new inhibitors were discovered 
and the mechanisms of inhibition were understood better. In the review paper by Palmqvist et al. [5], the old classification with the inhibitor groups short-chain organic acids, furans and phenols is used. Today, the classification is based on the chemical functional groups of the inhibitor. For example, in the review paper by Jakakody et al. [7], the four groups aldehydes, ketones, organic acids and phenols are used. This new classification supports the chemical description of the inhibitor, but does not describe the origin of the inhibitor. To gain better understanding about inhibitors, a modified categorization is used in this paper to point out both, the chemical properties and the origin of the inhibitor. The old category furans is replaced by the category sugar-derived aldehydes (Table 1), since it is difficult to categorize glycolaldehyde into any of the three old groups. The category phenols is exchanged for the category aromatic compounds (Table 1), since some of the inhibitors have phenolic origin but cannot be chemically categorized as phenols anymore, for example benzoic acid [20]. The group short-chain organic acids is extended into the group short-chain organic acids and aldehydes (Table 1) [7,21].

Table 1. Classification of lignocellulose inhibitors.

\begin{tabular}{|c|c|c|c|}
\hline Main Group & Subgroup & Inhibitors Examples & References \\
\hline $\begin{array}{l}\text { Sugar-derived } \\
\text { aldehydes }\end{array}$ & & $\begin{array}{l}\text { Glycolaldehyde, furfural, } \\
\text { hydroxymethylfurfural }\end{array}$ & {$[7,8,22]$} \\
\hline \multirow[t]{3}{*}{ Aromatic compounds } & Phenolic compounds & $\begin{array}{l}\text { Coniferyl aldehyde, vanillin, } \\
\text { syringaldehyde, } \\
\text { 4-hydroxybenzaldeyde, } \\
\text { 4-hydroxycoumaric acid, syringic } \\
\text { acid, vanillic acid, salicylic acid, } \\
\text { ferulic acid, 4-hydroxy-benzoic acid, } \\
\text { catechol, guaiacol etc. }\end{array}$ & {$[20,23,24]$} \\
\hline & $\begin{array}{l}\text { Non-phenolic } \\
\text { compounds }\end{array}$ & $\begin{array}{l}\text { Benzyl alcohol,cinnamaldehyde, } \\
\text { benzoic acid, cinnamic acid, para-and } \\
\text { ortho-toluic acid, } \\
\text { 3,4-dimethoxy-cinnamic acid etc. }\end{array}$ & {$[20]$} \\
\hline & Benzoquinones & $\begin{array}{l}\text { p-Benzoquinone, } \\
\text { 2,6-Dimethoxybenzoquinone etc. }\end{array}$ & [25] \\
\hline \multirow[t]{2}{*}{$\begin{array}{l}\text { Short-chain organic } \\
\text { acids and aldehydes }\end{array}$} & Short-chain organic acids & $\begin{array}{l}\text { Formic acid, acetic acid, lactic acid, } \\
\text { levulinic acid etc. }\end{array}$ & {$[5,23]$} \\
\hline & $\begin{array}{l}\text { Short-chain organic } \\
\text { aldehydes }\end{array}$ & Formaldehyde, acetaldehyde & {$[26,27]$} \\
\hline \multirow[t]{2}{*}{ Other inhibitors } & Sugars & $\begin{array}{l}\text { Monomeric and oligomeric pentoses } \\
(\text { e.g., xylose), glucose, cellobiose }\end{array}$ & [28] \\
\hline & Metals & copper, nickel, chromium, iron etc. & {$[20]$} \\
\hline
\end{tabular}

\subsection{Origin and Formation of Inhibitors}

Lignocellulosic biomass is broken down with the help of pretreatment methods. Those methods use physical, chemical and biological pathways to disrupt the compact structure of lignocellulosic biomass. During the pretreatment process, fermentable sugars are released, which originate from the structural polysaccharides-cellulose and hemicellulose. In addition to sugars, inhibitors are formed, which negatively influence the following hydrolysis and fermentation processes. The origin and formation mechanisms of inhibitors are diverse. One inhibitor can have different origins and different pathways of formation. The inhibitor's origin is mainly from cellulose, hemicellulose or lignin (Figure 1). Some inhibitors also originate from the extractives of lignocellulosic biomass or even derive from the pretreatment equipment, for example metals, like copper, nickel, chromium and iron [20]. 


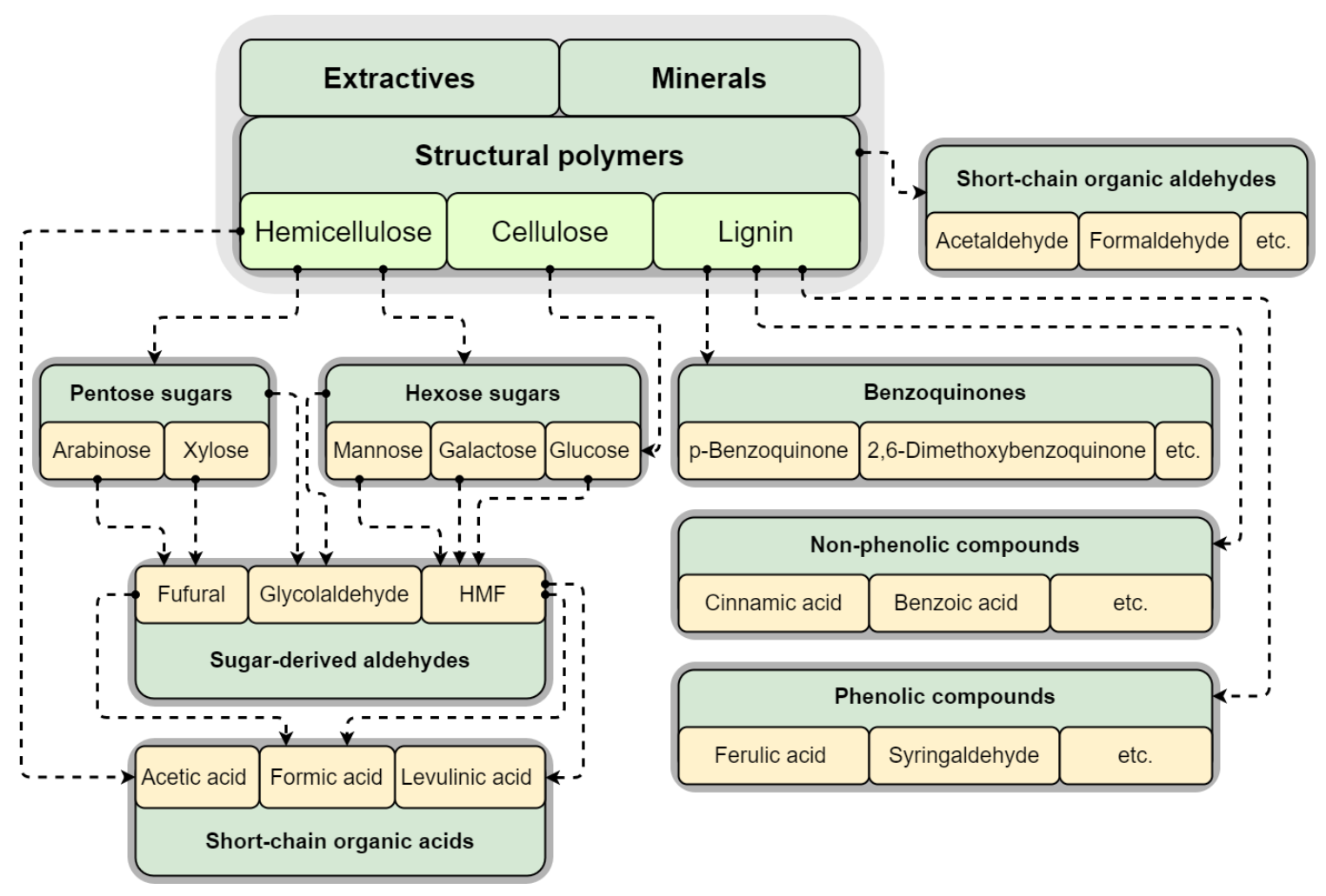

Figure 1. Origins of lignocellulosic inhibitors.

The formation of inhibitors depends on both, the pretreatment method and the feedstock composition. However, the feedstock composition plays a more important role in the formation of inhibitors than the pretreatment method. Especially the amount and the kind of inhibitor are influenced by the feedstock composition [23].

The pretreatment method can vary in pressure, temperature, $\mathrm{pH}$, duration, presence of water and added chemicals [7]. Depending on pretreatment parameters, the occurrence of inhibitors varies. Many inhibitors can be avoided if the $\mathrm{pH}$ of the pretreatment method is kept around 7 [20].

The feedstock composition depends on the type of lignocellulosic biomass used. It can be softwoods, hardwoods or annual plants. The types of biomass vary in their cellulose, hemicellulose, lignin, extractives and minerals content. Especially, the amounts and the compositions of hemicellulose and lignin are important, then most of the organic inhibitors derive from those parts. Depending on the type of biomass the development of a specific inhibitor in certain concentrations is more or less likely. For example, softwoods contain more lignin than hardwoods, consequently it is more likely that aromatic inhibitors are formed during the pretreatment of softwoods. Majority of inhibitors can be avoided simply by using biomass with low hemicellulose and lignin contents [5].

Additionally, the difference in the build-up of hemicellulose and lignin in softwoods, hardwoods and annual plants helps to understand the formation of inhibitors. Therefore, the main differences in the structure of hemicellulose and lignin of softwoods, hardwoods and annual plants is given here:

Hemicellulose:

- The hemicellulose of softwoods is mainly built up from the structural units $\mathrm{O}$-acetyl-galactoglucomannans and arabino-4-O-methylglucurono-D-xylans. The following sugars are found in those structural units: galactose, glucose, mannose, arabinose, 4-O-methylglucuronic acid and xylose.

- The hemicellulose of hardwoods is mainly built up from the structural unit $O$-acetyl-4-O-methylglucurono-D-xylans. The following sugars are found in this structural unit: 4-O-methylglucuronic acid and xylose 
- The hemicellulose of annual plants is mainly built up from the structural unit arabino-(O-acetyl-4-O-methylglucurono)-D-xylans. The following sugars are found in this structural unit: arabinose, 4-O-methylglucuronic acid and xylose. Additionally, the phenols-ferulic acid and $p$-coumaric acid can be attached to the arabinose sugar in the hemicellulose connecting the hemicellulose to the lignin $[20,29]$.

\section{Lignin:}

- The lignin of softwoods is mainly built up from guaiacyl units.

- The lignin of hardwoods is mainly built up from guaiacyl units and syringyl units.

- The lignin of annual plants contains all three major moieties-guaiacyl units, syringyl units and p-hydroxyphenyl units [20,23].

How the differences in lignin and hemicellulose in softwoods, hardwoods and annual plants affect the formation of certain inhibitors will be explained in Sections 3.3-3.5.

\subsection{Sugar-Derived Aldehydes}

Sugar-derived aldehydes are degradation products of various lignocellulose-based sugars (Figure 1). Those sugars are present in hemicellulose and cellulose of lignocellulosic biomass. Commonly, the sugar monomers are distinguished by their number of carbon atoms, C5- (pentoses) and C6-sugars (hexoses), and position and number of hydroxyl groups.

The hemicellulose of lignocellulosic biomass is composed of pentoses, such as D-xylose and L-arabinose, and hexoses, such as D-mannose, D-glucose and D-galactose. The cellulose is built-up from D-glucose, which forms a uniform crystalline grid in the biomass [5].

One of the most common sugar-derived aldehydes is glycolaldehyde. This inhibitor can originate from both hexoses and pentoses. Glycolaldehyde is mainly formed when a low concentration of water is used in the pretreatment method. Due to the low concentration of water, the favored formation reaction of glycolaldehyde is the fragmentation reaction.

Glycolaldehyde has the ability to form covalent bonds with macromolecules, such as proteins, DNA, and aminoresidues of cell membranes. This chemical linking disturbs the function of vital cell mechanisms and, thus, hinders the viability and reproduction of microorganisms (Figure 2) [7].

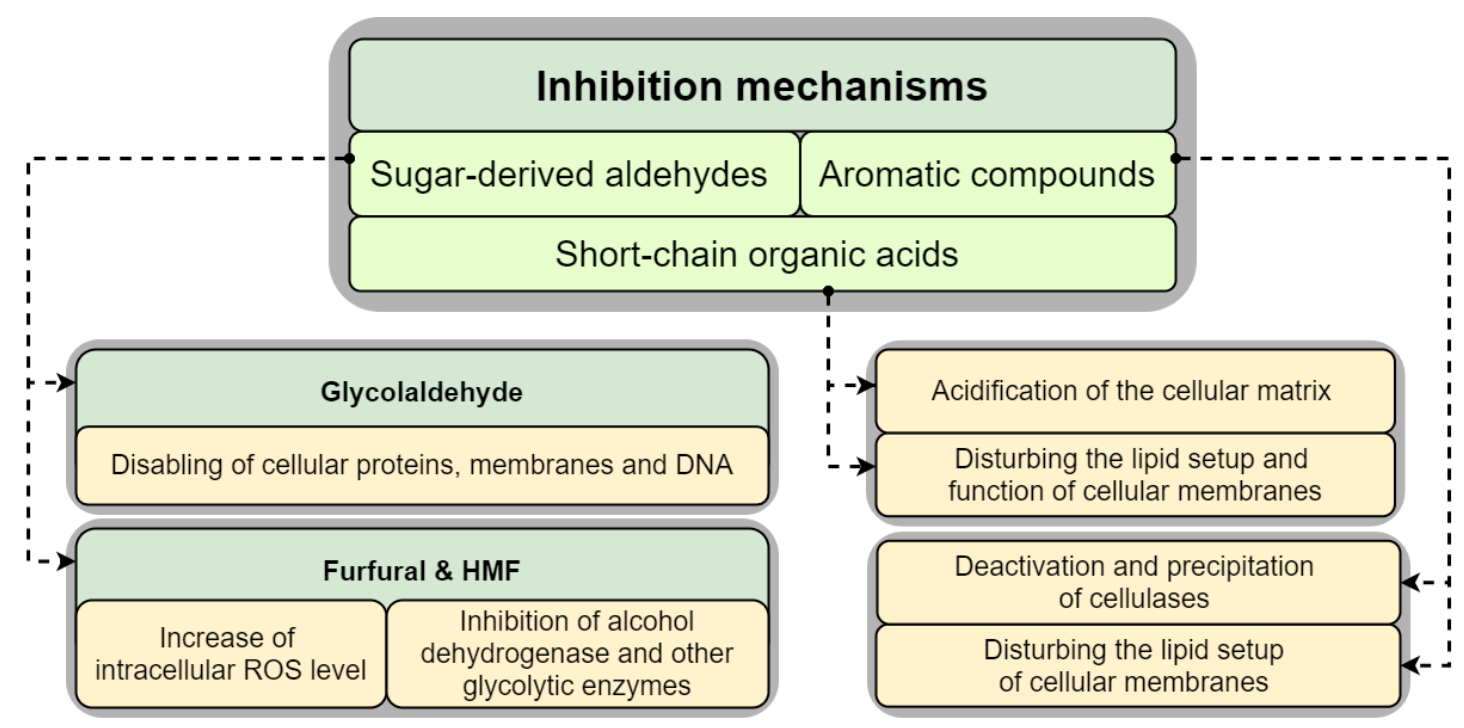

Figure 2. Inhibition mechanisms of lignocellulosic inhibitors.

Another common sugar-derived aldehyde is furfural. This inhibitor is a degradation product of pentoses, such as D-xylose and L-arabinose. Furfural is mainly formed when the pretreatment method 
is performed under acidic conditions, over a long period of time, in a high concentration of water, and under $150^{\circ} \mathrm{C}$. The favored chemical reaction in the formation of furfural is the dehydration reaction.

Furfural inhibits microbiological enzymes, such as alcohol dehydrogenase and other glycolytic enzymes. This kind of inhibition decreases the intracellular yield of ATP in Saccharomyces cerevisiae (yeast), thus hindering the yeast's growth as ATP is essential for this process. Furthermore, furfural induces the accumulation of reactive oxygen species (ROSes) in yeast. ROSes damage mitochondria, vacuole membranes, actin cytoskeleton and nuclear chromatin of the yeast (Figure 2). Overall, furfural hinders survival and reproduction of the yeast. A positive side effect is that the yeast's bioethanol production yields increase at a furfural concentration of $29 \mathrm{mmol} / \mathrm{L}[5,7,8,22,23,29]$.

The third well-known sugar-derived aldehyde is hydroxymethylfurfural. This inhibitor derives from the degradation of hexoses, such as D-mannose, D-glucose and D-galactose [5]. Pretreatment conditions for the formation of HMF are the same as for furfural. Additionally, it is assumed that the microbiological inhibition mechanism of HMF (Figure 2) is similar to that of furfural $[8,23]$.

It is also important to mention that furfural and HMF do not inhibit cellulases during the enzymatic hydrolysis of lignocellulosic biomass [28].

\subsection{Aromatic Compounds}

The inhibitor group aromatic compounds is divided into three subgroups: phenolic compounds, non-phenolic compounds and benzoquinones (Table 1). The first subgroup phenolic compounds contains inhibitors, which have at least one hydroxy-group attached to their aromatic ring. Some examples are coniferyl aldehyde, vanillin and syringaldehyde. The second subgroup is non-phenolic compounds. This subgroup contains inhibitors, which have a phenolic origin but cannot any longer be classified as phenols. Some examples are benzyl alcohol, cinnamaldehyde and benzoic acid $[20,23]$. The last subgroup is benzoquinones, which contains for example inhibitors such as $p$-Benzoquinone and 2,6-Dimethoxybenzoquinone [25].

Aromatic compounds have an aromatic benzene ring in their chemical structure. Most aromatic compounds, which occur after pretreatment of lignocellulosic biomass, derive from lignin (Figure 1), although some can also originate from hemicellulose or the extractives of lignocellulosic biomass [20]. To understand the actual origin of a certain aromatic compound, it is important to understand the function, formation and structure of lignin.

One common function of lignin is to protect the plant cell from pests and pathogens. As a result, the lignin structure is dense, complex and hard to degrade for most microbes. This recalcitrance is due to the strong chemical bonds between the lignin units, which are carbon-carbon and ether bonds $\left(\mathrm{R}-\mathrm{O}-\mathrm{R}^{\prime}\right)$ [20]. Additionally, compared to the crystalline grid of cellulose, the structure of lignin is less uniform. This non-uniform structure is an obstacle for most biomass-degrading enzymes.

The structure of lignin is synthesized in plants as follows: Firstly, the amino acids phenylalanine and tyrosine are metabolized to monolignols sinapyl, coniferyl and coumaryl alcohols. Then, those monolignols are randomly linked in a polymerization process called phenoxy-radical-coupling. Within the already synthesized lignin, structural units can be divided into guaiacyl, syringyl, and p-hydroxyphenyl [30].

Returning to the beginning of Section 3.2 and taking a closer look at the differences between lignins of softwoods, hardwoods and annual plants, it is possible to deduce the origin of certain aromatic inhibitors [29]. For example, vanillin and vanillic acid derive from the guaiacyl units of lignin. The guaiacyl units are present in the lignin of all three: softwoods, hardwoods and annual plants. Du et al. [23] found vanillin and vanillic acid in pine wood, poplar wood and corn stover hydrolysates, which represent softwoods, hardwoods, and annual plants, respectively.

Inhibitors such as syringic acid and syringaldehyde derive from the syringyl units of lignin. The syringyl units are mainly present in hardwoods and annual plants. Following according to Du et al. [23], the two inhibitors were present in higher quantities in the poplar wood and corn stover hydrolysates, but not in the pine wood hydrolysate. 
The inhibitor 4-hydroxybenzaldehyde originates from the $p$-hydroxyphenyl unit of lignin. This structural unit is mainly found in annual plants. Consequently, Du et al. [23] found 4-hydroxybenzaldehyde in higher quantities in the corn stover hydrolysate, but not in the poplar wood and pine wood hydrolysates.

Inhibitors, such as ferulic acid and 4-hydroxycinnamic acid, can originate from the monolignols-coniferyl alcohol and coumaryl alcohol. Those two monolignols play an important part in the linkage of hemicellulose and lignin in annual plants, such as various grasses [20]. As a result, Du et al. [23] found higher concentrations of ferulic acid and 4-hydroxycinnamic acid in the corn stover hydrolysate.

Thus far, the origins of the prevalent aromatic inhibitors were discussed; however, many other aromatic inhibitors exist that will be not addressed in this paper.

Aromatic compounds have been shown to inhibit both cellulases and microorganisms (Figure 2). Their microbiological inhibition is partly due to their hydrophobic properties. These properties allow them to intrude cellular membranes and cause a loss of the membrane integrity. As a result, the microbe's natural barrier against outside influences is damaged [5].

The enzymatic inhibition of aromatic compounds results in deactivation and precipitation of cellulases. The precipitation happens due to formation of aromatic compounds' complex around cellulases. Polyphenols, such as tannic acid, can precipitate cellulases while low-molecular-weight aromatic compounds, such as vanillin, syringaldehyde, cinnamic acid and hydroxybenzoic acid, inhibit B-glucosidases [28,31].

\subsection{Short-Chain Organic Acids and Aldehydes}

Short-chain organic acids can derive from different parts of lignocellulosic biomass (Figure 1). Thus, the concentration of those inhibitors in lignocellulosic hydrolysates is often higher than that of aromatic compounds. The inhibitive effects of short-chain organic acids are mainly towards microorganisms, such as yeasts and fermenting bacteria. Some examples for short-chain organic acids are formic, acetic, lactic and levulinic acids [5].

Acetic acid is mostly a degradation product of acetyl-groups that can be found in lignin and hemicellulose. In addition, acetic acid is also present in the extractives of lignocellulosic biomass [32]. The formation of acetic acid is independent of the used chemicals in the pretreatment process [23]. However, the concentration of acetic acid increases with the pretreatment temperature and duration, as Zhang et al. [29] demonstrated in a steam explosion process of corn stover. Furthermore, the type of used lignocellulosic biomass in the pretreatment process is influencing the formation of acetic acid as well. For example, the hemicellulose in hardwoods is more acetylated than in softwoods, thus, results in more acetic acid during the pretreatment of hardwoods [5]. Acetic acid is found nearly in every lignocellulosic hydrolysate after pretreatment. This is because the hemicellulose of softwoods, hardwoods, and annual plants is normally acetylated (see Section 3.2).

Acetic acid has been shown to inhibit the nutrient uptake of Saccharomyces cerevisiae [33]. Additionally, it has been reported that acetic acid is acidifying the intracellular matrix of microorganisms [34]. An adjustment of $\mathrm{pH}$ of the hydrolysate improves the acetic acid tolerance of fermenting microorganisms [35]. Meanwhile, it is important to mention that acetic acid has no negative influence on cellulases during hydrolysis [28].

Another short-chain organic acid often found in hydrolysate is formic acid. This acid is a degradation product of HMF and furfural. Zhang et al. [29] demonstrated in a steam explosion treatment of corn stover that, similarly to acetic acid, the concentration of formic acid increases with the pretreatment temperature and duration.

Some other short-chain organic acids are lactic and levulinic acids. Lactic acid is a degradation product of sugars and mainly occurs when the pretreatment method is alkaline. Levulinic acid is a degradation product of HMF and mainly occurs when the pretreatment method is acidic $[4,5,20,23]$. 
All mentioned acids are weak acids with a low $\mathrm{pK}_{\mathrm{a}}$. The $\mathrm{pK}_{\mathrm{a}}$ is an equilibrium constant that indicates at which $\mathrm{pH}$ the concentration of dissociated and undissociated acid molecules is equal. The undissociated acid molecule is liposoluble, thus, it can easily diffuse through cell membranes. As the intracellular matrix of cells is often $\mathrm{pH}$ neutral, the diffused undissociated acid molecule starts to dissociate inside the cell thus, acidifying the intracellular matrix. The acid anion cannot easily pass cell membranes due to its ionic form; however, the small, released $\mathrm{H}^{+}$-ions can enter the cell and contribute to the acidification of the intracellular matrix (Figure 2). Microorganisms try to keep up the natural homeostasis; consequently, they start to pump out the $\mathrm{H}^{+}$-ions from the cell. This process consumes energy in the form of ATP, which could be otherwise used for growth.

The dissociated acid molecule is less harmful for microorganisms than the undissociated acid molecule, because it gets repulsed at the outside of cell membrane and the cell just needs to deal with the released $\mathrm{H}^{+}$-ions. Therefore, it is advantageous to keep the $\mathrm{pH}$ of lignocellulosic hydrolysates over the $\mathrm{pK}_{\mathrm{a}} \mathrm{s}$ of the inhibitory acids. Thus, keeping the weak acids dissociated and unable to pass the cell membranes. For example, Saccharomyces cerevisiae prefers an external $\mathrm{pH}$ between 5-5.5, which is over the $\mathrm{pK}_{\mathrm{a}} \mathrm{s}$ of the discussed acids [5,36].

In addition to affecting the natural homeostasis, weak acids can also negatively influence the lipid setup and function of cell membranes (Figure 2). Furthermore, the stress caused by weak acids can decrease the synthesis rate of DNA and RNA inside the cell. However, weak acids are not only inhibiting, they can also improve fermentation. For example, low concentrations of acetic acid have shown to stimulate the production of bioethanol in Saccharomyces cerevisiae $[19,36]$.

Another inhibitory group is short-chain organic aldehydes. For example, formaldehyde and acetaldehyde belong to this group [26]. Martin et al. [27] found in a steam-exploded Norway spruce hydrolysate formaldehyde and demonstrated that it is strongly inhibiting the growth of Saccharomyces cerevisiae. Formaldehyde mainly originates from the degradation of lignin [27].

\subsection{Other Inhibitors}

Sugars that originate from lignocellulosic biomass are usually used for the production of bioethanol. However, sugars can also be inhibitory. Oligomeric and monomeric pentose sugars, glucose and cellobiose have been shown to inhibit cellulases during hydrolysis. As a result, the sugar concentration in lignocellulosic hydrolysate is important to avoid this kind of inhibition [28].

Another group of inhibitors is metals (Table 1). Ions of metals, such as copper, nickel, chromium and iron, have been demonstrated to inhibit microorganisms. Metal ions in the hydrolysate often originate from the pretreatment equipment or from the mineral part (ash) of the lignocellulosic biomass. The pretreatment equipment usually releases metal ions when the pretreatment conditions are acidic [20].

\subsection{Toxicity of Inhibitors}

The toxicity of inhibitors depends on different factors, such as $\mathrm{pH}$ and temperature of hydrolysate [35,37]. Furthermore, the toxicity of inhibitors is different for every microorganism, since every microbe has developed different levels of tolerance against different inhibitors. Additionally, the toxicity of inhibitors also depends on the concentration of the inhibitor in the hydrolysate. Therefore, as lignocellulosic hydrolysates and different microorganisms used for bioethanol production are not comparable, they cannot be used to evaluate the overall toxicity of any inhibitor [5].

\section{Detoxification Methods for Lignocellulosic Hydrolysates after Pretreatment}

\subsection{Chemical Degradation of Inhibitors}

The addition of chemicals to detoxify a lignocellulosic hydrolysate is already intensively investigated (Figure 3). 


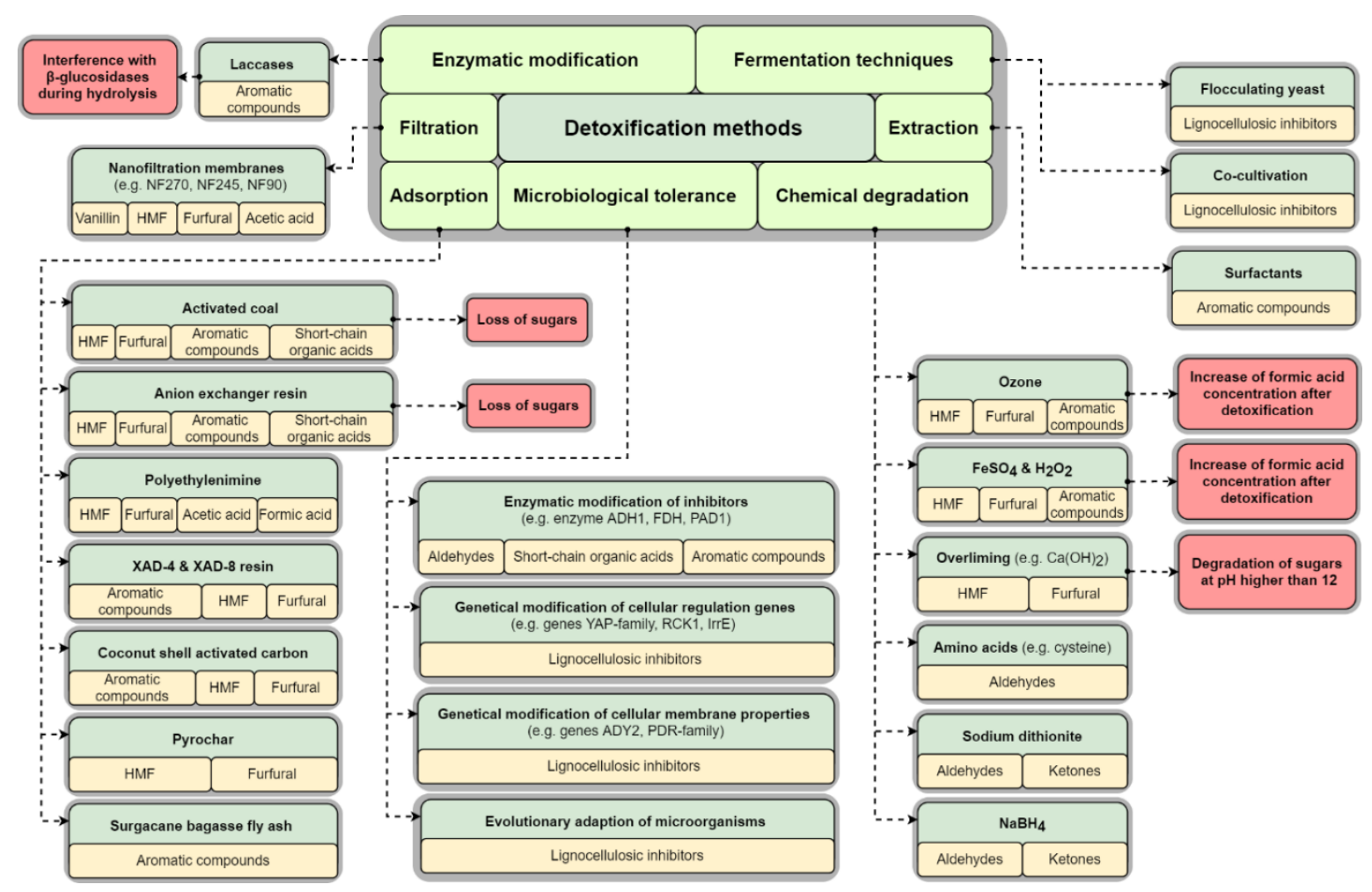

Figure 3. Different detoxification methods for lignocellulosic hydrolysates.

For example, ozone, which is used in the pulp and paper industry as bleaching chemical, was applied on a Norway spruce hydrolysate. Due to this, the aromatic compounds, furfural and HMF were effectively reduced in the hydrolysate. However, the reactive ozone increased the formic acid concentration in the hydrolysate, which makes the detoxified hydrolysate unsuitable for further fermentation [38].

Another detoxification method for lignocellulosic hydrolysates is overliming. In this method, the $\mathrm{pH}$ of the hydrolysates is increased with a base, such as $\mathrm{Ca}(\mathrm{OH})_{2}$, to 10 or higher. Due to the high $\mathrm{pH}$, inhibitors, such as HMF and furfural, degrade nearly completely. Aromatic compounds are slightly affected by the $\mathrm{pH}$ change as well while acetic acid is not affected by the high $\mathrm{pH}$ at all. The disadvantage of this treatment is that at a $\mathrm{pH}$ of 12 up to $70 \%$ of the sugars in the hydrolysate can be lost [39].

Cavka et al. [13] reported the utilization of sodium borohydride $\left(\mathrm{NaBH}_{4}\right)$ for detoxifying a Norway spruce hydrolysate. $\mathrm{NaBH}_{4}$ is effective in reducing ketone and aldehyde groups to hydroxyl groups. In this process. The concentration of aromatic compounds and sugar-derived aldehydes declined. $\mathrm{NaBH}_{4}$ improved the glucose consumption and ethanol production of yeast, but did not influence the performance of the enzymatic hydrolysis.

Additionally, sodium dithionite was tested on a spruce hydrolysate to obtain a comparison to $\mathrm{NaBH}_{4}$. Sodium dithionite is also effective in reducing aldehydes and ketones. It also improved the enzymatic hydrolysis and fermentation of the hydrolysate $[13,40]$.

Salt treatments (e.g., $\mathrm{NaCl}, \mathrm{CaCl}_{2}, \mathrm{CaSO}_{4} \ldots$ ) were also tested on lignocellulosic hydrolysates, but Persson et al. [41] point out that no significant inhibitor removal was achieved with those treatments.

Another inhibitor treatment is the addition of amino acids for the detoxification of hydrolysates. Especially cysteine with its thiol side group reacted with different inhibitors. The treatment increased the ethanol production rate of yeast from $0.18 \mathrm{~g} / \mathrm{L} / \mathrm{h}$ to $1.77 \mathrm{~g} / \mathrm{L} / \mathrm{h}$. The reaction products of cysteine and inhibitor showed no negative side effects on the fermentation. Additionally, the amino acid treatment is easy to apply, although the viability of the treatment for industrial processes is still unclear [42]. 
In wastewater treatment, ferrous sulfate $\left(\mathrm{FeSO}_{4}\right)$ and hydrogen peroxide $\left(\mathrm{H}_{2} \mathrm{O}_{2}\right)$ are used in combination for detoxification. Soudham et al. tested the ability of those substances on lignocellulosic hydrolysates. The chemicals did not change the concentrations of acetic acid, levulinic acid or glucose, though they reduced the concentrations of HMF, furfural and aromatic compounds. The concentration of formic acid increased during detoxification, probably due to degradation of HMF and furfural [43].

\subsection{Adsorption of Inhibitors}

Different adsorption materials (Figure 3) have been tested for their ability to remove inhibitors from lignocellulosic hydrolysates. The adsorption of inhibitors depends on the adsorbent surface area, pore size and its chemical properties. Furthermore, the adsorption is influenced by environmental conditions, such as temperature, $\mathrm{pH}$, and contact time between inhibitor and adsorbent [9]. Adsorption has one big advantage compared to other detoxification methods. The inhibitor is not chemically modified during adsorption and can be desorbed from the adsorbent and further utilized as valuable chemical in other industries.

Sugarcane bagasse fly ash was successfully used to adsorb aromatic compounds, such as tannic acid and vanillin, from a lignocellulosic hydrolysate. Since aromatic compounds have shown to inhibit cellulases, the removal of the aromatic compounds improved the enzymatic hydrolysis of the hydrolysate [44].

The usage of activated coal as inhibitor absorbent is already well investigated. It is effective in absorbing furfural, HMF, different aromatic compounds and short-chain organic acids, although it shows a poor adsorbent rate towards acetic acid [9]. Sarawan et al. [17] reported a maximum acetic acid absorption of $40 \%$. This came along with a sugar loss of $10 \%$, which is for an industrial process a high economic loss [17].

A cheaper adsorbent compared to activated coal is pyrochar. This adsorbent is produced from sludge from anaerobic digester, which is used for the biogas production. The pyrochar is effective in removing sugar-derived aldehydes, such as furfural and HMF [45].

Another adsorbent is polyethylenimine. This adsorbent has shown to adsorb the inhibitors HMF, furfural, acetic acid, and formic acid. The adsorbent was tested on a spruce hydrolysate. The adsorbent detoxified the hydrolysate to an extent that it was possible to ferment the hydrolysate at a biomass loading as high as $30 \%$. High-biomass loadings in hydrolysates are important to make an industrial bioethanol production process from lignocellulosic biomass feasible [46].

Furthermore, it was tested if ion exchange resins are capable to extract inhibitors from hydrolysates. In the paper by Nilvebrant et al. [47], it has been demonstrated that an anion-exchange resin (AG 1-X8, Bio-Rad) is able to adsorb aromatic compounds, HMF, furfural and short-chain organic acids, when the $\mathrm{pH}$ of the hydrolysate was adjusted to 10 . The disadvantage was that high amount of sugars were lost during the adsorption, which are necessary for fermentation. An XAD-8 was also effective in removing inhibitors, such as aromatic compounds, HMF, and furfural [47].

Another research was conducted on the usage of coconut shell activated carbon as adsorbent for inhibitors. The material was able to remove aromatic compounds and sugar-derived aldehydes and did not adsorb fermentable sugars [48].

Different inhibitors with different properties are formed during the pretreatment of lignocellulosic biomass, therefore not every absorbent is appropriate for every inhibitor. As a result, two different detoxification methods were combined in the research by Trinh et al. [49]. For removing short-chain organic acids from a poplar, hydrolysate electrodialysis was used. Then, a XAD-4 resin was used to absorb aromatic compounds and sugar-derived aldehydes from the hydrolysate [49].

\subsection{Extraction of Inhibitors}

Many inhibitors are valuable compounds, which can be used in the chemical industry. Thus, it would be an asset to be able to recover inhibitors from the hydrolysate broth. Liquid-liquid extraction 
(Figure 3) is intensely investigated as a recovery method. The major drawback is the biological toxicity of the most common extraction agents, usually organic solvents [11].

Recently, a detoxification application with surfactant-based cloud point extraction (CPE) was developed. This method uses surfactants, which are soluble in water at low temperatures and insoluble at high temperatures, enabling a two-phase extraction. The temperature-dependent extraction works due to the hydrophilic and hydrophobic parts of the surfactants. Dhamole et al. [50] showed that about $90 \%$ of the aromatic compounds could be removed from simulated hydrolysate. Another advantage of this method is that the surfactants are non-toxic to microorganisms. Additionally, no sugar-loss was observed when low concentrations of surfactants were used. The drawback is that the extraction shows no significant effect on the removal of HMF, furfural and acetic acid [50].

\subsection{Filtration of Inhibitors}

Different filtration products are available on the market. Separation of particles is already possible on a molecular basis, which means that even molecules can be separated from each other, depending on their size. The molecular separation belongs to the field of nanofiltration. The main principle of nanofiltration is that small molecules can permeate the membrane and bigger molecules are retained. Since the filtration happens on a molecular basis, the polarity of molecules plays an important role as well and can be crucial in whether molecules are retained or not [51].

In a model study by Qi et al. [16], two commercial nanofiltration membranes-NF270 and NF90 (Dow FilmTec) - were tested for their ability to separate sugars from inhibitors. An artificial hydrolysate containing xylose, glucose and furfural was prepared and used as a feed. The NF90 membrane showed a sugar rejection of $98.5 \%$ and a furfural transmission of $66.2 \%$. However, this efficient detoxification required a diafiltration process, which means higher quantities of water were necessary to remove furfural sufficiently. From the industrial process point of view, the additional process water should be avoided, since it increases the operational costs. Additionally, the separation efficiency of the membranes depends on the feed's temperature, permeation flux, $\mathrm{pH}$ and solutes concentration [16]. In a different model study by Nguyen et al. [10], nanofiltration and reversed osmosis membranes were assessed in their capability to remove inhibitors from hydrolysates. This study also used an artificial hydrolysate as a feed. The hydrolysate contained glucose, xylose and arabinose, representing the fermentable sugars, acetic acid, representing the organic acids, HMF and furfural, representing the sugar-derived aldehydes and vanillin, representing the aromatic inhibitors. Experiments on different membranes showed that nanofiltration membranes are more suitable for the detoxification of lignocellulosic hydrolysates than reversed osmosis membranes. The nanofiltration membranes showed a high sugar rejection of up to $>94 \%$ and an inhibitor transmission of up to $>80 \%$. Especially the tested nanofiltration membranes NF270, NF245, NF- (Dow FilmTec) and DK (GE Osmonics) are found to be suitable for the detoxification. On the other hand, the reversed osmosis membranes had a high sugar rejection of up to $97 \%$, but a lower inhibitor transmission compared to the nanofiltration membranes.

The main separation factor for nanofiltration membranes is the molecular size; however, vanillin was permeating through the membranes in high quantities, although it has a similar molecular weight as for example xylose, which was mainly rejected. It is assumed that the hydrophilicity of sugars is partly responsible for the high sugar rejection and the hydrophobicity of aromatic compounds for the high transmission, as in the case of xylose and vanillin. Nanofiltration can be a promising method for the detoxification of lignocellulosic hydrolysates without chemically modifying lignocellulosic inhibitors. Additionally, the overall sugar loss in nanofiltration process can be low if the membrane with the right pore size is used [10]. Still, further research is necessary to ensure that nanofiltration can be applied on real lignocellulosic hydrolysates, since the mentioned studies just used artificial hydrolysates.

\subsection{Microbiological Tolerance to Inhibitors}

Microbes have developed different methods to cope with lignocellulose-derived inhibitors. For instance, the cellular in situ detoxification of lignocellulosic hydrolysates can be achieved with enzymes, 
which chemically modify inhibitors to make them less toxic. In this case, the genetical expression of enzymes, such as oxidoreductases and dehydrogenases, is upregulated in microorganisms. Another approach is to change the cell membrane properties in order to change the fluidity and permeability of inhibitors through the cell membranes. Metabolic pathways can also be changed, which allow the cell to mitigate the negative effects of inhibitors or even to utilize the inhibitors as an important resource for their metabolism. Cells can also produce stress protectants, like trehalose, spermidine, glutathione and thioredoxin to increase the cell's inhibitor tolerance. Transporters and efflux pumps located at the cell membrane can help discard inhibitors. Regulation genes play an important part in the inhibitor resistance as well, since the activity of these genes is highly upregulated during inhibitor exposure [14,15].

\subsubsection{Enzymatic Modification of Inhibitors by Microorganisms}

Every inhibitor has a certain chemical structure and certain chemical properties. Those can cause severe problems in microorganisms and subsequently hinder growth and metabolism. As a result, microbes have developed different enzymes (Figure 3) to chemically modify inhibitors to convert them into their less toxic forms.

Aldehydes can be reduced into respective alcoholic forms with the help of enzymes and $\mathrm{NADH}$ or NADPH as cofactor. For example, HMF and furfural can be catalyzed to their less toxic forms-furan-2,5-dimethanol and 2-furanmethanol, respectively. The NADH-dependent enzyme YNL124C encoded by Saccharomyces cerevisiae is capable to reduce HMF, furfural and other aldehydes. The enzyme has the best operating conditions at a temperature of $20^{\circ} \mathrm{C}$ and at a $\mathrm{pH}$ of 4.5 [52]. A furfural reductase, produced by Escherichia coli LYO1, is able to reduce furfural. Additionally, the enzyme is able to reduce the inhibitor benzaldehyde to benzyl alcohol. This NADPH-dependent enzyme showed its best performance at $50^{\circ} \mathrm{C}$ and $\mathrm{pH}$ of 7 [53]. A different aldehyde reductase encoded by Saccharomyces cerevisiae from the gene ARI1 is able to reduce HMF, furfural, cinnamaldehyde and other aldehydes into their alcoholic forms. At a temperature of $25^{\circ} \mathrm{C}$ and $\mathrm{pH}$ of 7 , this NADPH-dependent enzyme has its optimum operation conditions. Saccharomyces cerevisiae also encodes other enzymes, with aldehyde reductase activity from the genes ADH1, ADH4, ADH6, ADH7, GRE2 and GRE3 [14].

Another big group of inhibitors are acids, which also undergo different metabolic modifications. Depending on the molecular size of the acid, the enzymatic modification can be different. For example, in the study by Sanda et al. [54], the Saccharomyces cerevisiae tolerance against formic acid and acetic acid was improved. The study genetically enhanced the activity of the enzymes transaldolase and formate dehydrogenase (FDH). The enzyme FDH is able to convert formic acid into $\mathrm{CO}_{2}$ with the help of $\mathrm{NAD}+$ as a cofactor. This metabolic pathway provides additional energy for the cell in form of NADH. Furthermore, in this study, the modified Saccharomyces cerevisiae strain was hybridized with a different Saccharomyces cerevisiae strain, having the same genetic modifications. Following a diploid strain was created, which exhibited a higher tolerance to acetic and formic acids than its haploid relative [54,55].

In some cases, acids can be utilized as valuable resources for metabolic purposes. For example, Ding et al. [33] enhanced in one study the expression of the gene ACS2 in Saccharomyces cerevisiae, which encodes the enzyme Acetyl-coenzyme A synthetase 2. The enzyme uses acetate for the synthesis of Acetyl-coenzyme A. Following the extracellular acetic acid concentration decreased and the yeast showed a higher growth rate and shortened lag-phase compared to the control [33].

In the paper by Brandt et al. [15] the genes for the enzyme acetylating acetaldehyde dehydrogenase (AADH) from Escherichia coli, Piromyces sp. E2 and Clostridium beijerinckii were inserted into Saccharomyces cerevisiae SR8. Those genes enable a metabolic pathway to degrade acetic acid to acetaldehyde and finally to ethanol. Thus, the degradation of acetic acid contributes also to the bioethanol production. The only disadvantage of this pathway is that it consumes energy in the form of ATP and NADH for the degradation [15].

Larger molecule inhibitor acids, like ferulic acid and cinnamic acid, can be degraded through a different metabolic pathway in Saccharomyces cerevisiae. In the study by Mukai et al. [56], the genes 
PAD1 and FDC1 were overexpressed in Saccharomyces cerevisiae. PAD1 encodes for the enzyme phenylacrylic acid decarboxylase and FDC1 for the enzyme ferulic acid decarboxylase; together, they convert phenylacrylic acids to their corresponding non-toxic vinyl-derivatives. It is assumed that the PAD1 gene provides the necessary cofactors for the decarboxylation reaction and FDC1 is conducting the reaction [15]. The enzymes are capable of reducing the inhibitors' cinnamic acid, $p$-coumaric acid, and ferulic acid to styrene, 4-vinylphenol, and 4-vinylguaiacol, respectively [56].

Another group of inhibitors are benzoquinones. These are lignin-derived inhibitors, which can disable growth and metabolism of microorganisms. In the study by Yan et al. [25], a degradation ability of Zymomonas mobilis was discovered, which enabled a reduction of $p$-benzoquinone to hydroquinone. Additionally, five key genes were detected and overexpressed, which subsequently increased Z. mobilis tolerance against $p$-benzoquinone [25].

The enzymatic modification of inhibitors consumes energy in the form of ATP, NADH, and NADPH. Since this necessary energy is mainly regenerated through the degradation of sugars, it is important to optimize the metabolic pathways of the cellular energy production.

The ethanol production by Saccharomyces cerevisiae takes place under anaerobic conditions. As a result, the most effective energy production pathways, which require oxygen, are not operating. Therefore, the energy production is lowered and the inhibitor detoxification efficiency decreased. Additional energy sources can help to cope with this problem. For example, unmodified Saccharomyces cerevisiae is not capable to consume xylose, although it is the most abundant sugar in lignocellulosic hydrolysates after glucose. Furthermore, xylose can contribute to the bioethanol production and provide additional energy for the inhibitor degradation. Thus, different xylose-consuming Saccharomyces cerevisiae strains have been genetically engineered.

An genetical improvement of the citric acid cycle in cells can also provide additional energy for the inhibitor degradation [14].

NADH and NADPH in Saccharomyces cerevisiae is used for the reduction of aldehyde inhibitors. A cellular redox imbalance can occur if the yeast cell is focusing too much on the inhibitor degradation. Therefore, it is important to maintain a balance between $\mathrm{NAD}(\mathrm{P})+$ and $\mathrm{NAD}(\mathrm{P}) \mathrm{H}$ in the cell, otherwise it can be damaged and subsequently, lose its function [7].

\subsubsection{Enhanced Inhibitor Resistance by Modification of Regulation Genes}

Increased inhibitor tolerance in microorganisms can also be achieved with the overexpression of regulation genes (Figure 3), which are connected to inhibitor tolerance and energy production.

For instance, the regulation gene IrrE from the extremophilic bacterium Deinococcus radiodurans was inserted and overexpressed in Saccharomyces cerevisiae. As a consequence, the yeast's tolerance to HMF, furfural, acetic acid and formic acid improved. The IrrE gene amplifies DNA repair mechanisms in the cell, which resulted in an improved inhibitor resistance [57].

In the study by Oh et al. [58], the Saccharomyces cerevisiae regulation gene RCK1 was overexpressed. The overexpression achieved an increased acetic acid tolerance. Additionally, a decrease of the intracellular ROS level was noticed. The RCK1 gene plays an important role in the oxidative stress response [58].

Other regulation genes can be overexpressed in Saccharomyces cerevisiae, too, improving inhibitor tolerance. For instance, the overexpression of the genes of the YAP-family increases the yeast's inhibitor tolerance. The genes of the YAP-family are important regulators of the cellular stress response [14].

\subsubsection{Increased Inhibitor Resistance by Modification of Membrane Properties}

Modification of cell membrane properties (Figure 3) can also improve the inhibitor tolerance of microorganisms. For example, in the study by Zhang et al. [59] the ADY2 gene for an acetate transporter in Saccharomyces cerevisiae was deleted. Consequently, the yeast's tolerance to acetic acid increased [15,59]. 
The genes of the PDR-family, which encode for plasma membrane proteins and are responsible for cellular transportation, can be genetically modified as well to improve the inhibitor tolerance of Saccharomyces cerevisiae [14].

\subsubsection{Evolutionary Adaption and Genetic Mining}

It is difficult to engineer a multi-inhibitor resistant strain for the fermentation of lignocellulosic hydrolysates, as a deep understanding of the genome is necessary, which is still lacking. As a result, scientists choose a different approach to engineer multi-inhibitor-resistant strains' evolutionary adaption (Figure 3). This method focuses on spontaneous mutation, which is achieved when microbes are exposed to environmental stress (inhibitors). Evolutionary adaption is often applied on industrial strains, as those have to adapt to new industrial process conditions. To adapt a strain in an evolutionary process, different cultivation systems, such as serial-shake-flask cultivation, sequential-batch-reactor cultivation or continuous cultivation are used.

The drawback of evolutionary adaption is that the engineered strains are just adapted to one certain environment and are sensitive to environmental changes. For example, one engineered strain can ferment one certain lignocellulosic hydrolysate, but is not capable to ferment another one with a different composition [15].

In the study by Narayanan et al. [35], it was attempted to develop a Saccharomyces cerevisiae strain with the ability to tolerate low $\mathrm{pH}$ and inhibitors, such as HMF, furfural, vanillin and acetic acid. After an evolutionary short-term adaption, a strain with those abilities was gained. To conserve the tolerances of the new strain, a long-term adaption was applied. After the long-term adaption, the strain was recultivated under stress-free conditions. Surprisingly, the strain showed low robustness, when it was exposed to low $\mathrm{pH}$ and inhibitors. It is assumed that a population heterogeneity during the short-term adaption was responsible for the increased $\mathrm{pH}$ and inhibitor resistance. This would explain why the strain after the long-term adaption was not capable to resist low $\mathrm{pH}$ and inhibitors, since it was recultivated as a homogenous culture [35].

The genetic pool of lab microorganisms regarding inhibitor resistances is limited. Hence, it is useful to exploit the genetic information of natural strains, which have already adapted to environmental stress in nature. Additionally, it is important to focus not only on the genes, which are overexpressed in microorganisms during stress conditions, but also on the suppressed genes [14,15].

\subsection{Laccase Treatment}

A major part of inhibitors derives from lignin in the form of aromatic compounds. Enzymes, such as laccases (Figure 3), can detoxify those aromatic compounds. Laccases are copper-containing phenoloxidases, which polymerize aromatic compounds, such as syringaldehyde. This polymerization process detoxifies the lignocellulosic hydrolysate [60].

Aromatic compounds, such as $p$-coumaric acid and ferulic acid, are grafted to the lignin structure by laccases, when solid lignin is present in the hydrolysate. This grafting process increases the lignin concentration in the hydrolysate and detoxifies the hydrolysate.

The drawback of laccases is the reduced sugar recovery after hydrolysis, since laccases interfere with b-glucosidases during hydrolysis and b-glucosidases are necessary for the cellulose break down. Therefore, it is recommended to perform the laccase treatment after hydrolysis [61].

\subsection{Fermentation Techniques for the Degradation of Inhibitors}

Many detoxification methods concentrate on the direct removal or degradation of inhibitors. Yet, the fermentation process (Figure 3) can also be optimized, improving the fermentability of lignocellulosic hydrolysates. For example, breweries use Saccharomyces cerevisiae strains, which form flocs during fermentation. The yeast flocs have a bigger diameter compared to single yeast cells, following this property simplifies the filtration process after fermentation. Additionally, the coagulating yeast is more tolerant to lignocellulosic inhibitors than its non-coagulating relative. The reason for this 
increased inhibitor tolerance is not understood well. It is assumed that the yeast flocs form a chemical barrier for inhibitors, which they cannot easily pass.

Yeast starts to coagulate, when it is exposed to environmental stress. Under the stress conditions yeast is expressing the necessary proteins for cell-cell adhesion to coagulate. Additionally, it is assumed that yeast is expressing tolerance factors against inhibitors during the coagulation process. For the fermentation of lignocellulosic hydrolysates and to overcome the negative side effects of inhibitors, it is useful to use coagulating yeast cultures instead of non-coagulating ones [62].

Different evolutionary engineering techniques are used to create a Saccharomyces cerevisiae strain with high inhibitor tolerance. Yet, this inhibitor tolerance goes hand in hand with low biomass concentrations and low bioethanol production rates. However, both of those factors are necessary to achieve an effective bioethanol production. In the study by Zhu et al. [63], two Saccharomyces cerevisiae strains with different capabilities were co-cultivated. One strain showed high inhibitor tolerance, the other one was capable to utilize high amounts of xylose during fermentation. The best inoculum ratio for those two strains was 1:10 (inhibitor-tolerant yeast: xylose-consuming yeast). When this ratio was not considered, the two strains competed with each other for the glucose in the hydrolysate. The co-cultivation of those two strains enabled an effective fermentation of a non-detoxified corn stover hydrolysate. This shows that it is useful to ferment lignocellulosic hydrolysates in a heterogeneous culture system, which allows to combine different abilities of Saccharomyces cerevisiae to enable an effective bioethanol production [63].

\section{Future Perspective}

Lignocellulosic inhibitors hinder a sufficient bioethanol production [4] and make utilization of lignocellulosic biomass as a cheap feedstock economically unfeasible. Consequently, different detoxification methods have been developed to remove lignocellulosic inhibitors. However, those methods increase the bioethanol production costs, which then impedes the profitability of the production. As a result, the detoxification method needs to be inexpensive, flexible, easy to apply and effective. Hence, different detoxification methods will be discussed here that correspond to those parameters.

A simple way to avoid inhibitors, such as furfural and HMF, is the $\mathrm{pH}$ adjustment to 7 during the pretreatment of biomass [20]. Furthermore, an $\mathrm{pH}$ adjustment of the hydrolysate after pretreatment helps microorganisms to withstand the negative effects of acid inhibitors [5]. Adding of metal ions (e.g., calcium) in certain concentrations can increase the acid-inhibitor-tolerance of microorganisms as well [64].

The engineering of multi-inhibitor-tolerant microorganisms for the bioethanol production has been considered as a promising way to overcome the negative effects of lignocellulosic inhibitors. Some improvements in this field have been achieved, but the engineered strains have shown to be tolerant to just one inhibitor or to a specific group of inhibitors. Additionally, the strains have been mainly tested in a specific hydrolysate, which makes it unclear whether the strains would be able to work with the same efficiency in a different hydrolysate. Besides that, the microbiological detoxification of hydrolysates consumes cellular energy, consequently other cellular parts in microorganisms obtain less energy. This issue, reduces the reproduction and endangers the viability of cells. In this sense, it would be an advantage to ferment lignocellulosic hydrolysates simultaneously with different strains to compensate the drawbacks of each modified strain. Co-cultivation systems combine different abilities, such as inhibitor degradation and xylose-utilization for bioethanol production. Furthermore, lignocellulosic hydrolysate might not require further detoxifications steps, when those co-cultivation systems are applied for fermentation. Additionally, the strains might be more flexible regarding the used lignocellulosic hydrolysates. Zhu et al. [63] already demonstrated that this co-cultivation system is possible, but further research is necessary to ensure the applicability of this idea in industry.

A required step in the detoxification of lignocellulosic hydrolysates is the removal of aromatic inhibitors, especially since they inhibit both the enzymatic hydrolysis and fermentation [5]. Adsorption is a promising method to remove aromatic inhibitors. The adsorbent should be nonpolar, since the 
majority of aromatic inhibitors is nonpolar. XAD-4 or XAD-8 resins feature this property $[47,49]$. Cheap adsorbents produced from biomass residues can be used as well, although they have been shown to also adsorb fermentable sugars [17,48].

Most detoxification methods concentrate on the complete removal or degradation of inhibitors. However, a complete elimination is not always required, since some inhibitors, such as acetic acid and furfural, in low concentrations have proven to increase the Bioethanol production in microorganisms $[5,19]$. Additionally, the incomplete elimination of lignocellulosic inhibitors lowers production costs, which then has a positive effect on the bioethanol sale price.

It has been discussed how to remove inhibitors and how to decrease their negative effects. However, the composition of lignocellulosic biomass plays an important role in the occurrence of lignocellulosic inhibitors as well. Many lignocellulosic inhibitors derive from lignin or/and hemicellulose. Consequently, many inhibitors can be avoided when the lignocellulosic biomass has a low hemicellulose and lignin content [20]. Additionally, chemical analysis of the lignocellulosic biomass can help to balance the lignin and hemicellulose content in the bioethanol production process. It could be also possible to ferment different lignocellulosic biomasses simultaneously, since the lignin and hemicellulose content in the hydrolysate can be controlled by chemical analysis of the biomass. Further research is necessary to confirm this idea.

Application of lignocellulosic inhibitors in other industries and also their further processing into other chemicals has not been discussed yet. Whether lignocellulosic inhibitors will be considered as an important source for different base chemicals, is unclear, especially since the concentration of some inhibitors in the hydrolysate is really low, which makes their extraction questionable. To determine the usage of lignocellulosic inhibitors, further research is necessary.

\section{Conclusions}

It is clear that lignocellulosic inhibitors have a negative effect on bioethanol production from lignocellulosic biomass. Those inhibitors occur in a wide variety with different properties and toxicity mechanisms. On the other hand, various detoxification methods have been developed to eliminate the negative effects of those inhibitors. Not every detoxification method is able to remove every inhibitor from lignocellulosic hydrolysates, but a combination of different detoxification methods can help overcome this problem as well. Additionally, inhibitors can be considered as a valuable resource for industries. The usage of lignocellulosic inhibitors in the industry is also supporting the main idea of biorefinery usage of biomass to produce chemicals. Furthermore, some inhibitors, for example, acetic acid, have in certain concentrations a stimulating effect on the bioethanol production [19]. With this in mind, it should be considered whether it is necessary to remove all inhibitors from lignocellulosic hydrolysates.

The main problem that bioethanol production from lignocellulosic biomass faces, is the fact that it cannot compete with the costs and efficiency of the production of bioethanol from agricultural crops yet [65]. A further development of detoxification and pretreatment methods, and a molecular understanding about formation and impact of lignocellulosic inhibitors, can help to solve this issue.

Author Contributions: N.S., Conceptualization, Writing-Original Draft Preparation, Writing-Review and Editing; T.K., Conceptualization, Writing-Review and Editing, Supervision and Project Administration. All authors have read and agreed to the published version of the manuscript.

Funding: The authors gratefully acknowledge the financial support of the European Regional Development Fund via the Mobilitas Pluss (project MOBERA1) of the Estonian Research Council and base financed project of EMU PM180260TIBT.

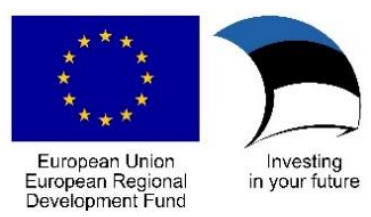


Conflicts of Interest: The authors declare no conflict of interest.

\section{References}

1. Rooni, V.; Raud, M.; Kikas, T. The freezing pre-treatment of lignocellulosic material: A cheap alternative for Nordic countries. Energy 2017, 139, 1-7. [CrossRef]

2. Raud, M.; Krennhuber, K.; Jäger, A.; Kikas, T. Nitrogen explosive decompression pre-treatment: An alternative to steam explosion. Energy 2019, 177, 175-182. [CrossRef]

3. Tu, W.-C.; Hallett, J.P. Recent advances in the pretreatment of lignocellulosic biomass. Curr. Opin. Green Sustain. Chem. 2019, 20,11-17. [CrossRef]

4. Kim, D. Physico-Chemical Conversion of Lignocellulose: Inhibitor Effects and Detoxification Strategies: A Mini Review. Mol. J. Synth. Chem. Nat. Prod. Chem. 2018, 23, 309. [CrossRef] [PubMed]

5. Palmqvist, E.; Hahn-Hagerdal, B. Fermentation of lignocellulosic hydrolysates. II: Inhibitors and mechanisms of inhibition. Bioresour. Technol. 2000, 74, 25-33. [CrossRef]

6. Almeida, J.R.; Modig, T.; Petersson, A.; Hähn-Hägerdal, B.; Lidén, G.; Gorwa-Grauslund, M.F. Increased tolerance and conversion of inhibitors in lignocellulosic hydrolysates by Saccharomyces cerevisiae. J. Chem. Technol. Biotechnol. 2007, 82, 340-349. [CrossRef]

7. Jayakody, L.N.; Ferdouse, J.; Hayashi, N.; Kitagaki, H. Identification and detoxification of glycolaldehyde, an unattended bioethanol fermentation inhibitor. Crit. Rev. Biotechnol. 2017, 37, 177-189. [CrossRef]

8. Wikandari, R.; Sanjaya, A.P.; Millati, R.; Karimi, K.; Taherzadeh, M.J. Chapter 20-Fermentation Inhibitors in Ethanol and Biogas Processes and Strategies to Counteract Their Effects. In Biomass, Biofuels, Biochemicals: Biofuels: Alternative Feedstocks and Conversion Processes for the Production of Liquid and Gaseous Biofuels, 2nd ed.; Pandey, A., Larroche, C., Dussap, C.-G., Gnansounou, E., Khanal, S.K., Ricke, S., Eds.; Academic Press: Cambridge, MA, USA, 2019; pp. 461-499, ISBN 978-0-12-816856-1.

9. Deng, F.; Cheong, D.-Y.; Aita, G.M. Optimization of activated carbon detoxification of dilute ammonia pretreated energy cane bagasse enzymatic hydrolysate by response surface methodology. Ind. Crops Prod. 2018, 115, 166-173. [CrossRef]

10. Nguyen, N.; Fargues, C.; Guiga, W.; Lameloise, M.-L. Assessing nanofiltration and reverse osmosis for the detoxification of lignocellulosic hydrolysates. J. Membr. Sci. 2015, 487, 40-50. [CrossRef]

11. Tomek, K.J.; Castillo Saldarriaga, C.R.; Cordoba Velasquez, F.P.; Liu, T.J.; Hodge, D.B.; Whitehead, T.A. Removal and upgrading of lignocellulosic fermentation inhibitors by in situ biocatalysis and liquid-liquid extraction. Biotechnol. Bioeng. 2015, 112, 627-632. [CrossRef]

12. Liu, Z.L.; Slininger, P.J.; Dien, B.S.; Berhow, M.A.; Kurtzman, C.P.; Gorsich, S.W. Adaptive response of yeasts to furfural and 5-hydroxymethylfurfural and new chemical evidence for HMF conversion to 2,5-bis-hydroxymethlfuran. J. Ind. Microbiol. Biotechnol. 2004, 31, 345-352. [CrossRef] [PubMed]

13. Cavka, A.; Jönsson, L.J. Detoxification of lignocellulosic hydrolysates using sodium borohydride. Bioresour. Technol. 2013, 136, 368-376. [CrossRef]

14. Liu, Z.L. Molecular mechanisms of yeast tolerance and in situ detoxification of lignocellulose hydrolysates. Appl. Microbiol. Biotechnol. 2011, 90, 809-825. [CrossRef] [PubMed]

15. Brandt, B.A.; Jansen, T.; Görgens, J.F.; van Zyl, W.H. Overcoming lignocellulose-derived microbial inhibitors: Advancing the Saccharomyces cerevisiae resistance toolbox. Biofuels Bioprod. Biorefining 2019, 13. [CrossRef]

16. Qi, B.; Luo, J.; Chen, X.; Hang, X.; Wan, Y. Separation of furfural from monosaccharides by nanofiltration. Bioresour. Technol. 2011, 102, 7111-7118. [CrossRef] [PubMed]

17. Sarawan, C.; Suinyuy, T.N.; Sewsynker-Sukai, Y.; Gueguim Kana, E.B. Optimized activated charcoal detoxification of acid-pretreated lignocellulosic substrate and assessment for bioethanol production. Bioresour. Technol. 2019, 286, 121403. [CrossRef]

18. Varanasi, P.; Singh, P.; Auer, M.; Adams, P.D.; Simmons, B.A.; Singh, S. Survey of renewable chemicals produced from lignocellulosic biomass during ionic liquid pretreatment. Biotechnol. Biofuels 2013, 6, 14. [CrossRef]

19. Casey, E.; Sedlak, M.; Ho, N.W.Y.; Mosier, N.S. Effect of acetic acid and pH on the cofermentation of glucose and xylose to ethanol by a genetically engineered strain of Saccharomyces cerevisiae. FEMS Yeast Res. 2010, 10, 385-393. [CrossRef] 
20. Jönsson, L.J.; Martín, C. Pretreatment of lignocellulose: Formation of inhibitory by-products and strategies for minimizing their effects. Bioresour. Technol. 2016, 199, 103-112. [CrossRef]

21. Palmqvist, E.; Hahn-Hägerdal, B. Fermentation of lignocellulosic hydrolysates. I: Inhibition and detoxification. Bioresour. Technol. 2000, 74, 17-24. [CrossRef]

22. García-Aparicio, M.P.; Ballesteros, I.; González, A.; Oliva, J.M.; Ballesteros, M.; Negro, M.J. Effect of inhibitors released during steam-explosion pretreatment of barley straw on enzymatic hydrolysis. Appl. Biochem. Biotechnol. 2006, 129, 278-288. [CrossRef]

23. Du, B.; Sharma, L.N.; Becker, C.; Chen, S.-F.; Mowery, R.A.; van Walsum, G.P.; Chambliss, C.K. Effect of varying feedstock-pretreatment chemistry combinations on the formation and accumulation of potentially inhibitory degradation products in biomass hydrolysates. Biotechnol. Bioeng. 2010, 107, 430-440. [CrossRef] [PubMed]

24. Jung, Y.H.; Kim, K.H. Chapter 3-Acidic Pretreatment. In Pretreatment of Biomass; Pandey, A., Negi, S., Binod, P., Larroche, C., Eds.; Elsevier: Amsterdam, The Netherlands, 2015; pp. 27-50, ISBN 978-0-12-800080-9.

25. Yan, Z.; Gao, X.; Gao, Q.; Bao, J. Identification, tolerance mechanism and metabolic modification of biorefinery fermentation strains to lignin derived inhibitor $p$-benzoquinone. Appl. Environ. Microbiol. 2019. [CrossRef] [PubMed]

26. Cavka, A.; Stagge, S.; Jonsson, L.J. Identification of Small Aliphatic Aldehydes in Pretreated Lignocellulosic Feedstocks and Evaluation of Their Inhibitory Effects on Yeast. J. Agric. Food Chem. 2015, 63, 9747-9754. [CrossRef]

27. Martín, C.; Wu, G.; Wang, Z.; Stagge, S.; Jönsson, L.J. Formation of microbial inhibitors in steam-explosion pretreatment of softwood impregnated with sulfuric acid and sulfur dioxide. Bioresour. Technol. 2018, 262, 242-250. [CrossRef]

28. Kim, Y.; Ximenes, E.; Mosier, N.S.; Ladisch, M.R. Soluble inhibitors/deactivators of cellulase enzymes from lignocellulosic biomass. Enzyme Microb. Technol. 2011, 48, 408-415. [CrossRef]

29. Zhang, Y.; Wang, L.; Chen, H. Formation kinetics of potential fermentation inhibitors in a steam explosion process of corn straw. Appl. Biochem. Biotechnol. 2013, 169, 359-367. [CrossRef]

30. Horwath, W. Chapter 12-Carbon Cycling: The Dynamics and Formation of Organic Matter. In Soil Microbiology, Ecology and Biochemistry, 4th ed.; Paul, E.A., Ed.; Academic Press: Cambridge, MA, USA, 2015; pp. 339-382, ISBN 978-0-12-415955-6.

31. Ximenes, E.; Kim, Y.; Mosier, N.; Dien, B.; Ladisch, M. Deactivation of cellulases by phenols. Enzyme Microb. Technol. 2011, 48, 54-60. [CrossRef]

32. Klinke, H.B.; Thomsen, A.B.; Ahring, B.K. Inhibition of ethanol-producing yeast and bacteria by degradation products produced during pre-treatment of biomass. Appl. Microbiol. Biotechnol. 2004, 66, 10-26. [CrossRef]

33. Ding, J.; Holzwarth, G.; Penner, M.H.; Patton-Vogt, J.; Bakalinsky, A.T. Overexpression of acetyl-CoA synthetase in Saccharomyces cerevisiae increases acetic acid tolerance. Fems Microbiol. Lett. 2015, 362. [CrossRef]

34. Gao, J.; Feng, H.; Yuan, W.; Li, Y.; Hou, S.; Zhong, S.; Bai, F. Enhanced fermentative performance under stresses of multiple lignocellulose-derived inhibitors by overexpression of a typical 2-Cys peroxiredoxin from Kluyveromyces marxianus. Biotechnol. Biofuels 2017, 10, 79. [CrossRef]

35. Narayanan, V.; Sànchez i Nogué, V.; van Niel, E.W.J.; Gorwa-Grauslund, M.F. Adaptation to low pH and lignocellulosic inhibitors resulting in ethanolic fermentation and growth of Saccharomyces cerevisiae. AMB Express 2016, 6. [CrossRef] [PubMed]

36. Mira, N.P.; Teixeira, M.C.; Sá-Correia, I. Adaptive Response and Tolerance to Weak Acids in Saccharomyces cerevisiae: A Genome-Wide View. OMICS J. Integr. Biol. 2010, 14, 525-540. [CrossRef] [PubMed]

37. Wallace-Salinas, V.; Gorwa-Grauslund, M.F. Adaptive evolution of an industrial strain of Saccharomyces cerevisiae for combined tolerance to inhibitors and temperature. Biotechnol. Biofuels 2013, 6. [CrossRef] [PubMed]

38. Cavka, A.; Wallenius, A.; Alriksson, B.; Nilvebrant, N.-O.; Jonsson, L.J. Ozone detoxification of steam-pretreated Norway spruce. Biotechnol. Biofuels 2015, 8, 196. [CrossRef]

39. Millati, R.; Niklasson, C.; Taherzadeh, M.J. Effect of $\mathrm{pH}$, time and temperature of overliming on detoxification of dilute-acid hydrolyzates for fermentation by Saccharomyces cerevisiae. Process Biochem. 2002, 38, 515-522. [CrossRef] 
40. De Vries, J.G.; Kellogg, R.M. Reduction of aldehydes and ketones by sodium dithionite. J. Org. Chem. 1980, 45, 4126-4129. [CrossRef]

41. Persson, P.; Andersson, J.; Gorton, L.; Larsson, S.; Nilvebrant, N.O.; Jonsson, L.J. Effect of different forms of alkali treatment on specific fermentation inhibitors and on the fermentability of lignocellulose hydrolysates for production of fuel ethanol. J. Agric. Food Chem. 2002, 50, 5318-5325. [CrossRef]

42. Xie, R.; Tu, M.; Carvin, J.; Wu, Y. Detoxification of biomass hydrolysates with nucleophilic amino acids enhances alcoholic fermentation. Bioresour. Technol. 2015, 186, 106-113. [CrossRef]

43. Soudham, V.P.; Brandberg, T.; Mikkola, J.-P.; Larsson, C. Detoxification of acid pretreated spruce hydrolysates with ferrous sulfate and hydrogen peroxide improves enzymatic hydrolysis and fermentation. Bioresour. Technol. 2014, 166, 559-565. [CrossRef]

44. Freitas, J.V.; Farinas, C.S. Sugarcane Bagasse Fly Ash as a No-Cost Adsorbent for Removal of Phenolic Inhibitors and Improvement of Biomass Saccharification. ACS Sustain. Chem. Eng. 2017, 5, 11727-11736. [CrossRef]

45. Monlau, F.; Sambusiti, C.; Antoniou, N.; Zabaniotou, A.; Solhy, A.; Barakat, A. Pyrochars from bioenergy residue as novel bio-adsorbents for lignocellulosic hydrolysate detoxification. Bioresour. Technol. 2015, 187, 379-386. [CrossRef] [PubMed]

46. Cannella, D.; Sveding, P.V.; Jørgensen, H. PEI detoxification of pretreated spruce for high solids ethanol fermentation. Appl. Energy 2014, 132, 394-403. [CrossRef]

47. Nilvebrant, N.O.; Reimann, A.; Larsson, S.; Jonsson, L.J. Detoxification of lignocellulose hydrolysates with ion-exchange resins. Appl. Biochem. Biotechnol. 2001, 91-93, 35-49. [CrossRef]

48. Freitas, J.V.; Nogueira, F.G.E.; Farinas, C.S. Coconut shell activated carbon as an alternative adsorbent of inhibitors from lignocellulosic biomass pretreatment. Ind. Crops Prod. 2019, 137, 16-23. [CrossRef]

49. Trinh, L.T.P.; Kundu, C.; Lee, J.-W.; Lee, H.-J. An integrated detoxification process with electrodialysis and adsorption from the hemicellulose hydrolysates of yellow poplars. Bioresour. Technol. 2014, 161, 280-287. [CrossRef]

50. Dhamole, P.B.; Wang, B.; Feng, H. Detoxification of corn stover hydrolysate using surfactant-based aqueous two phase system. J. Chem. Technol. Biotechnol. 2013, 88, 1744-1749. [CrossRef]

51. Nagy, E. Chapter 15-Nanofiltration. In Basic Equations of Mass Transport through a Membrane Layer, 2nd ed.; Nagy, E., Ed.; Elsevier: Amsterdam, The Netherlands, 2019; pp. 417-428, ISBN 978-0-12-813722-2.

52. Zhao, X.; Tang, J.; Wang, X.; Yang, R.; Zhang, X.; Gu, Y.; Li, X.; Ma, M. YNL134C from Saccharomyces cerevisiae encodes a novel protein with aldehyde reductase activity for detoxification of furfural derived from lignocellulosic biomass. Yeast 2015, 32, 409-422. [CrossRef]

53. Gutierrez, T.; Ingram, L.O.; Preston, J.F. Purification and characterization of a furfural reductase (FFR) from Escherichia coli strain LYO1-An enzyme important in the detoxification of furfural during ethanol production. J. Biotechnol. 2006, 121, 154-164. [CrossRef]

54. Sanda, T.; Hasunuma, T.; Matsuda, F.; Kondo, A. Repeated-batch fermentation of lignocellulosic hydrolysate to ethanol using a hybrid Saccharomyces cerevisiae strain metabolically engineered for tolerance to acetic and formic acids. Bioresour. Technol. 2011, 102, 7917-7924. [CrossRef]

55. Popov, V.O.; Lamzin, V.S. NAD(+)-dependent formate dehydrogenase. Biochem. J. 1994, 301, $625-643$. [CrossRef]

56. Mukai, N.; Masaki, K.; Fujii, T.; Kawamukai, M.; Iefuji, H. PAD1 and FDC1 are essential for the decarboxylation of phenylacrylic acids in Saccharomyces cerevisiae. J. Biosci. Bioeng. 2010, 109, 564-569. [CrossRef] [PubMed]

57. Luo, P.; Zhang, Y.; Suo, Y.; Liao, Z.; Ma, Y.; Fu, H.; Wang, J. The global regulator IrrE from Deinococcus radiodurans enhances the furfural tolerance of Saccharomyces cerevisiae. Biochem. Eng. J. 2018, 136, 69-77. [CrossRef]

58. Oh, E.J.; Wei, N.; Kwak, S.; Kim, H.; Jin, Y.-S. Overexpression of RCK1 improves acetic acid tolerance in Saccharomyces cerevisiae. J. Biotechnol. 2019, 292, 1-4. [CrossRef]

59. Zhang, M.; Zhang, K.; Mehmood, M.A.; Zhao, Z.K.; Bai, F.; Zhao, X. Deletion of acetate transporter gene ADY2 improved tolerance of Saccharomyces cerevisiae against multiple stresses and enhanced ethanol production in the presence of acetic acid. Bioresour. Technol. 2017, 245, 1461-1468. [CrossRef] [PubMed]

60. Ji, L.; Shen, Y.; Xu, L.; Peng, B.; Xiao, Y.; Bao, X. Enhanced resistance of Saccharomyces cerevisiae to vanillin by expression of lacA from Trametes sp AH28-2. Bioresour. Technol. 2011, 102, 8105-8109. [CrossRef] [PubMed] 
61. Oliva-Taravilla, A.; Moreno, A.D.; Demuez, M.; Ibarra, D.; Tomas-Pejo, E.; Gonzalez-Fernandez, C.; Ballesteros, M. Unraveling the effects of laccase treatment on enzymatic hydrolysis of steam-exploded wheat straw. Bioresour. Technol. 2015, 175, 209-215. [CrossRef]

62. Landaeta, R.; Aroca, G.; Acevedo, F.; Teixeira, J.A.; Mussatto, S.I. Adaptation of a flocculent Saccharomyces cerevisiae strain to lignocellulosic inhibitors by cell recycle batch fermentation. Appl. Energy 2013, 102, 124-130. [CrossRef]

63. Zhu, J.-Q.; Li, X.; Qin, L.; Li, W.-C.; Li, H.-Z.; Li, B.-Z.; Yuan, Y.-J. In situ detoxification of dry dilute acid pretreated corn stover by co-culture of xylose-utilizing and inhibitor-tolerant Saccharomyces cerevisiae increases ethanol production. Bioresour. Technol. 2016, 218, 380-387. [CrossRef]

64. Zhao, H.; Li, J.; Wang, J.; Xu, X.; Xian, M.; Liu, H.; Zhang, H. Calcium Supplementation Abates the Inhibition Effects of Acetic Acid on Saccharomyces cerevisiae. Appl. Biochem. Biotechnol. 2017, 181, 1573-1589. [CrossRef]

65. Ayodele, B.V.; Alsaffar, M.A.; Mustapa, S.I. An overview of integration opportunities for sustainable bioethanol production from first- and second-generation sugar-based feedstocks. J. Clean. Prod. 2020, 245, 118857. [CrossRef]

(C) 2020 by the authors. Licensee MDPI, Basel, Switzerland. This article is an open access article distributed under the terms and conditions of the Creative Commons Attribution (CC BY) license (http://creativecommons.org/licenses/by/4.0/). 